This item was submitted to Loughborough's Research Repository by the author.

Items in Figshare are protected by copyright, with all rights reserved, unless otherwise indicated.

\title{
'the whole window just shatters into a million pieces and it doesn't make any sound': an examination of 'affordance' and situational cues for theft from a motor vehicle
}

\section{PLEASE CITE THE PUBLISHED VERSION}

https://doi.org/10.1057/s41284-018-0136-3

\section{PUBLISHER}

(c) Macmillan Publishers Ltd., part of Springer Nature

\section{VERSION}

AM (Accepted Manuscript)

\section{PUBLISHER STATEMENT}

This work is made available according to the conditions of the Creative Commons Attribution-NonCommercialNoDerivatives 4.0 International (CC BY-NC-ND 4.0) licence. Full details of this licence are available at: https://creativecommons.org/licenses/by-nc-nd/4.0/

\section{LICENCE}

CC BY-NC-ND 4.0

\section{REPOSITORY RECORD}

Quinn, Anthony, and Louise E. Grove. 2019. "'the Whole Window Just Shatters into a Million Pieces and It Doesn't Make Any Sound': An Examination of 'affordance' and Situational Cues for Theft from a Motor Vehicle". figshare. https://hdl.handle.net/2134/33230. 
'the whole window just shatters into a million pieces and it doesn't make any sound' ${ }^{1}$ - An examination of 'affordance' and situational cues for Theft from Motor Vehicle.

\section{Abstract:}

Much offending, particularly acts of acquisitive crime, is influenced by whether there is a discernible opportunity to take advantage of. The success of this can be determined by the presence or absence of certain characteristics in the immediate environment and how they are interpreted to facilitate gain by an offender. This study explores some of these techniques or 'affordances' that have been adopted by individuals when seeking to commit Theft from Motor Vehicle offences. This insight is gleaned through qualitative one-to-one interviews with participants who have received criminal convictions for this crime type. There is an evaluation of how offender awareness of affordances could lead to the vulnerability of certain contexts as subsequently, ideas of countermeasures against these offending opportunities are offered.

\section{Keywords:}

Theft from Motor Vehicle; offender perspectives; situational cues, affordance; environmental criminology.

Words: 7070

Mr Anthony Quinn, PhD Researcher, Loughborough University - a.quinn@lboro.ac.uk Dr Louise Grove, Senior Lecturer in Criminology and Social Policy, Loughborough University l.e.grove@lboro.ac.uk

${ }^{1}$ Quotation taken from the interview with Paul who discussed a technique which could be used to enter a motor vehicle. 
$\underline{\text { Introduction }}$

According to police recorded data in 2016-17, there were 407,000 vehicle-related thefts in England and Wales. The figure recorded by the Crime Survey for England and Wales was even higher and reported the occurrence of 790,000 vehicle-related thefts (Office for National Statistics, 2017). Although much reduced from its peak in the mid-1990s, vehicle-related theft evidently remains a high-volume crime. One of the categories encompassed within this crime type is Theft from Motor Vehicle (TFMV) (see Gov.uk, 2017). In this article, we focus upon TFMV which is defined as the stealing of property from inside or on a motor vehicle (Gov.uk, 2017). TFMV is one of four 'Vehicle Offences'; the others are: Aggravated Vehicle Taking, Theft or Unauthorised Taking of a Motor Vehicle and Interfering with a Motor Vehicle (Gov.uk, 2017).

Previous work that addresses TFMV has been predominantly quantitative in nature, focusing on spatial and temporal patterns of victimisation (Johnson et al. 2006; 2009) and discernible links with domestic burglary (Johnson et al. 2009). These analyses have concluded that TFMV offences can "cluster in both space and time. That is, when an event occurs at one location another is likely to occur soon after. To use the vocabulary of an epidemiologist, like burglary the risk of vehicle crime is communicable" (Johnson et al. 2006: 45). It was found that, of a significant volume of TFMV offences, "just under $40 \%$ of events took place within 14 days and $400 \mathrm{~m}$ of an earlier event, one half in less than 28 days" (Johnson et al. 2006: 32). Thus, following on from an initial TFMV offence being committed, there is a significant possibility that further offences will occur soon after in close proximity (Johnson et al. 2006). There also appears to be a preference for where vehicles are located when they are targeted; $28 \%$ of TFMV offences are reported to occur against motor vehicles located on a residential driveway whilst $45 \%$ occur against vehicles parked on the street (The AA, 2012). For vehicle crime more generally, clear patterns in the locations where vehicle thefts occur have been documented (Suresh and Tewksbury, 2012; Lockwood, 2012) and an increased vulnerability has been reported for vehicles situated in areas where there is a density of roads with a high volume of targets (Copes, 1999). Qualitative interviews with TFMV offenders have been carried out but these have focused mainly upon criminal careers (Light et al. 1993) or the context of a specific prevention project (Sampson, 2004); detailed study of how vehicle crime is committed within certain contexts appears unexplored.

It has been identified where these offences might cluster but less emphasis has been placed on why they might cluster in specific contexts. It is precisely this aspect of TFMV, and the decision-making process and interpretations it involves, that is the subject of the present paper. The structure of which is as follows: first, the theoretical framework that informed the research approach is explored, 
drawing on environmental criminology and the concept of 'affordance'. Previous literature, which addresses domestic burglary, is used to provide a foundation for how the constitution of place might facilitate the commission of TFMV. Situational cues have been documented for domestic burglary (see Bennett and Wright, 1984; Nee and Taylor, 2000; Palmer et al. 2002; Nee, 2003; Nee and Meenaghan, 2006; Armitage, 2017), but there does not appear to have been as much endeavour for TFMV offences. There has been an examination of the importance of improved design in certain settings to reduce the likelihood of vehicle crime offences going undetected (Bromley and Thomas, 1997) but little beyond this. In the third section, the qualitative methods used to analyse offender decision-making are discussed. The paper then moves towards a discussion of the perceptions offenders had of locations subject, or close, to repeated TFMV victimisation and possible affordances that could be perceived within them. This could help to give a nuanced understanding of how and why TFMV offences have been committed in these locales and what needs to be realised to prevent this outcome in the future. Lastly, the key findings and conclusions of the study are made alongside recommendations for future research.

\section{Literature Review}

Crime is not random. It is concentrated in time and space (Sherman et al. 1989; Spelman and Eck, 1989; Lee et al. 2017). This concentration manifests itself as repeat victimisation, which occurs when a person, place or business is criminally targeted on more than one occasion (see Grove and Farrell, 2012). The perpetrator can be the same or a different offender but usually it is the former (Pease and Laycock, 1999). If we can gain insight into how, where, and when a crime is likely to occur, we can implement measures designed to reduce risk (Farrell and Pease, 1993; Pease, 1998). We know that reducing repeat victimisation is an effective way of reducing crime more broadly but that efforts need to be tailored to the specific context (Tilley, 1993; Grove et al. 2012). An important consideration for understanding crime in different contexts is to examine 'how an individual moves through the environment' (Andresen et al. 2010: 183) at particular times and in particular places (Brantingham and Brantingham, 1981, Felson, 2014). The focus of this piece concerns a notion proposed by Brantingham and Brantingham (1978) that 'an individual who is motivated to commit a crime uses cues (either learned through experience or learned through social transmission) from the environment to locate and identify targets or victims' (Andresen et al. 2010: 233).

The impact of these cues on offender thought processes during target selection has been explored for the acquisitive crime type of domestic burglary (see Armitage, 2017). Significant findings from engagement with burglars are that some cues lead to decisions of avoidance (Armitage, 2017) whilst 
others have the opposite effect and lead to the attractiveness of residential property (see Bennett and Wright, 1984; Nee and Taylor, 2000). Moreover, 'offending behaviour is rarely the result of an inexorable drive to commit crime, but more a learned response to sets of factors that have been successful in the past' (Nee and Taylor, 2000: 47). Instead, it has been found that 'the typical burglar was far less opportunistic than had previously been assumed, with the majority demonstrating discrimination and expertise at the scene of the crime rather than responding impulsively to random opportunities' (Nee and Taylor, 2000: 47). This idea of criminal 'expertise' within specific environments has strong resonance with, and invites examination of, a concept termed 'affordance' (Gibson, 2015).

The theory of 'affordance' is an ecological approach that focuses on perception (Gibson, 1988; Gibson, 2015). It involves cognition in so far as the meaning of things are interpreted by the organism or individual, as they seek to assess their immediate environment (Gibson, 1988). Crucially, this is not to state that meaning is susceptible to change but rather that the requirements of the individual will result in meaning being perceived differently (Gibson, 2015). It is stated that the affordance of something does not change as the need of the observer changes. The observer may or may not perceive or attend to the affordance, according to his needs, but the affordance, being invariant, is always there to be perceived' (Gibson, 2015: 130). Norman (1988) later contributed that objects can have a perceived meaning or use as well as an actual use. An example of perceived use versus actual use is provided by Garwood (2009) who depicts how a 'wheelie bin' can be used to store and move stolen goods as much as it can be used as a storage facility for waste. To refer again to cues that might be experienced during a domestic burglary, Wortley (2012) discusses the possible utility of a garden table and chairs. For a savvy burglar, these items constitute useful tools to reach and enter the window of a property that might otherwise seem inaccessible, or at least not a risk to the safety of the property (Wortley, 2012).

This link between experience, expertise and perception of opportunity has been documented by Wickström (2006). He states: 'people differ in what alternatives they see and what choices they make in a particular setting depending on who they are (i.e., their knowledge and skills, experiences and morality) and the characteristics of the setting (e.g., opportunities and frictions and their moral context)' (Wickström 2006: 62). As well as detailing the importance of knowledge, skills and subsequent expertise, Wickström (2006) recognises individual morality as an important consideration. Within a crime context, any individual might be receptive towards an affordance but this circumstance will not be realised if they are morally disinclined to offend (Wickström, 2006). An essential component of the Routine Activity Theory is the 'likely' offender (Cohen and Felson, 1979; Felson, 2014) without whom offending behaviour cannot occur. The focus here are the situational 
cues or affordances as they are interpreted by individuals if already motivated to offend. These micro-level stimuli have also been referred to as 'situations that prompt' (Wortley, 1997) or 'opportunity cues' (Lab, 2016) and their interpretation as 'event-level decisions' (Johnson, 2010). Our point of analysis here is how offender decision-making is influenced by these factors. This involves scrutiny of locations where offences have repeatedly occurred and an assessment of influences on decisions to offend (Wortley, 1997). Essentially, a consideration of 'affordance' can lead to insight into how features of particular contexts present a possibility for criminal behaviour.

The features of offending contexts can be understood through 'precipitators' which include: prompts, pressures, permissions and provocations (Wortley, 2017). Each of these has a role to play in shaping the behaviour of a potential offender but we engage mainly with prompts because they are 'aspects of the immediate environment that bring to the surface thoughts, feelings and desires' (Wortley, 2017: 67); in effect, they are observable and the immediate impressions they evoke can be explained by those who have offended. This is not to suggest that there is an elevated importance of 'prompts' however it is outside the scope of the present paper to systematically explore each precipitator (Wortley, 2017); instead, these will be explored in further detail in future work. Close consideration should be paid towards the properties of prompts within the offending environment and their individual contribution assessed. How they are interpreted has much to do with the desired goal of the individual (Ekblom, 2012) as it does with the prompt. This resonates with the idea that the affordance of something is always there to be perceived, it just depends on the intention (Gibson, 2015). Some prompts will be regarded as positive towards a course of action and others will be regarded as negative (Ekblom, 2012). Prompts that trigger a positive goal might cause an outcome to occur whilst negative prompts are those to be avoided or prevented (Ekblom, 2012). To take, once more, the example of a garden table and chairs, they provide entry to a window and could be regarded as positive because they allow entry to the property. Individuals in the vicinity who could spot someone mounting a table and chairs, would be classed as a negative prompt because their gaze is to be avoided if the goal of entry is to be successful. Put simply, 'perception is central' (Garwood, 2011: 37).

There are various forms that prompts can take and ideas associated with domestic burglary can be used as a framework to examine TFMV. An open second story window could trigger a skilled burglar to look for a garden table and chairs to take advantage of a perceived opportunity (Wortley, 2012). Uncollected newspapers outside a property with an open window could indicate a vacant property (Wortley, 2017). Building contactors wearing high visibility clothing in the nearby area might lead a receptive burglar to imitate such a dress code to fit in at that location (Wortley, 2017). A lack of environmental beautification (Wortley, 2017), around the property with the open window, could 
indicate to a potential burglar that the residents do not care for their homes and neighbours (Wilson and Kelling, 1982) and that irregular behaviour in the area is unlikely to be challenged (Wilson and Kelling, 1982). An opportunity, provided by a property with a visibly open window, is situated amongst various other 'cues' (Brantingham and Brantingham, 1978) that will either add to or negate from target suitability. The study of crime at place should provide an appreciation of which 'prompts' (Wortley, 2017) tend to signify a suitable opportunity and which do not. Furthermore, an enhanced understanding of the 'affordance' of certain features of the built environment (Gibson, 1988; Ekblom, 2012; Gibson, 2015) is likely to facilitate the discovery of how offences are committed. This could be informative for dynamic future crime prevention efforts (Newman et al. 2016); particularly in places that have been subject to disproportionate rates of repeat victimisation (Grove et al. 2012).

\section{Focus of current study}

Contextual influences like 'prompts' (Wortley, 2017) and 'affordances' (Gibson, 1988; Ekblom, 2012; Gibson, 2015), and their role in the decision-making of offenders when committing Theft from Motor Vehicle (TFMV) will be investigated. Of interest is what, if anything, individuals who have committed TFMV can shed on situational cues considered at the time of offending. In a similar vein to Lasky et al. (2017), the decision-making process of individuals who have committed the offence under study is the primary, most relevant, point of focus. Whilst TFMV is an acquisitive crime type like domestic burglary, it is possible there are differences as well as similarities in the way opportunities are perceived by a motivated offender (Cohen and Felson, 1979). Whether particular affordances are attended to (Gibson, 2015) when committing acts of TFMV does not appear to have been explored. If an essential step for the advancement of crime prevention, particularly against repeat victims, is to increase the range of crime types placed under study (Grove, 2011), existing findings must be diversified. The next section offers insight into how offender accounts were obtained and the contextual details which can explain why TFMV offences might be repeatedly committed, through the realisation of affordances, at certain locations.

\section{Methods and Data}

The data collection method for this study involved qualitative one-to-one interviews with individuals who had received criminal convictions for TFMV. Conducting offender-based research is not a new method but has been pursued in several studies relating to acquisitive crime (see Bennett and Wright, 1984; Ashton et al. 1998; Nee and Taylor, 2000; Palmer et al. 2002; Nee and Meenaghan, 2006; Armitage, 2017; Lasky et al. 2017). The utility of this method is highlighted by the 
recommendation that: 'to learn about crime, including how to prevent it, criminologists should go to the source. As a collective, criminals are the preeminent source of knowledge on crime' (Jacques and Bonomo, 2017: 9). Participants were recruited with the assistance of the Derbyshire, Leicestershire, Nottinghamshire and Rutland Community Rehabilitation Company (the DLNR CRC) which works alongside the National Probation Service (England and Wales) to supervise offenders under probation (The DLNR CRC, 2014). The regionalisation of the East Midlands Community Rehabilitation Company, which serves the neighbouring counties of Derbyshire, Leicestershire, Nottinghamshire and Rutland (The DLNR CRC, 2014), meant that contact was initially made through this wider organisation. All participants who took part stated that their town/city of residence was within the county of Leicestershire (England) and so this study involved asking individuals resident in Leicestershire about situational contexts within the same county.

Probation Practitioners working for the DLNR CRC acted as gatekeepers and controlled research access (Saunders, 2006). If an individual on a probation license had at least one criminal conviction for TFMV, they were invited to interview by one of the gatekeepers on behalf of the researcher. Participants were then given a participant information sheet which contained details about the scope of the research and the value of their participation. Probation Practitioners were able to access the criminal convictions for each individual that they were in charge of supervising. This form of sampling fits what has been termed as a convenience sample since participants were selected based upon their accessibility and suitability (Bryman, 2016). All who were willing to take part were asked to sign informed consent forms which promised confidentiality, anonymity and the right to withdraw from the research process at any time before completion of the study; it was also made clear that data would be stored for ten years upon completion of the project which is in line with the data collection and storage stipulations of $* * * * *$ University (nd). Interviews were recorded with an audio recorder and the recordings were stored in a secure location and accessible only to the researcher through entry of a passcode; this adheres to the Code of Ethics of the British Society of Criminology (2006). The study was granted full approval by ***** University Ethics Board.

It was of paramount importance at the outset of the interviews to reiterate that only offences that had come to the attention of the police could be discussed; this was to avoid mention of any undetected offences since the researcher was ethically obliged to report these to the appropriate authorities. No reward was offered to participants but refreshments were provided during the interviews which all took place on DLNR CRC premises. This was a stipulation of the ethical approval that was granted to ensure the safety of the researcher during the interview process. This also helped to improve the quality of the data that was obtained because being introduced to the participant by a probation practitioner facilitated an element of trust with the participants and the 
absence of practitioners during the interview possibly gave participants a freedom to be open. Like other research which has engaged with offenders within criminal justice facilities (see for example Zetinigg and Gaderer, 2011; Polišenská, 2011 Armitage, 2018), there was a mixed reaction to the undertaking of this research. Whilst at one probation centre staff took a keen interest to learn about the project and to search their caseloads for relevant participants, at another, practitioners could spare less time for what was regarded as an external project (see Zetinigg and Gaderer, 2011). Despite this difference, every effort was made to ensure an equal number of participants was recruited from each regional probation office, relative to its size. This was necessary to increase the chances of recruiting individuals who had offended in a variety of areas. 11 participants were eligible to discuss TFMV offences and collectively they had received 136 convictions for TFMV offences. Participants were between the ages of 20 and 42 and all were male. The audio recordings were transcribed and later coded using the qualitative data software package NVivo 10.

Interviewees were first asked close-ended demographic questions relating to: age, gender, town/city of residence and to the number of vehicle crime convictions they had received. Participants were then shown a series of photographs on a tablet computer which depicted four locations containing motor vehicles; their perceptions of these locations were probed through open-ended questions. The tablet computer allowed the participant to zoom in and out as they desired. These locations were either places where there had been high rates of TFMV repeat victimisation or places close by. These areas were pinpointed using police recorded crime data supplied by Leicestershire Police and a 'Near Repeat Calculator' (Temple University, 2015) using a similar process to that used by Johnson et al. (2006). The four locations were all situated within the county of Leicestershire (England) but participants were not told any information about them such as where they were or why they had been selected. They were simply asked to describe what they saw within the images and later to rank them in order of most safe, in terms of vehicle crime, to least safe. These 'proxy observational methods' (Nee, 2010: 233) can be 'memory enhancing' (Nee, 2010: 231) and that appeared to be the case within the interviews conducted for this study. Once asked to describe what they could see, participants began to describe intricate details within the locations. Indeed, it was through this task that a wealth of 'cues' (Brantingham and Brantingham, 1978) and some affordances (Gibson, 1988; Gibson, 2015) came to light. Examples of some of the visual images can be found in the Appendix. In the following section, the content of these interviews is analysed. The names that are referenced are all pseudonyms. 


\section{Offender Perceptions of Vulnerable Contexts}

This section is laid out to first document situational cues or prompts that can demonstrate a suitable location to offend, before moving to inspect some of the affordances said to facilitate the commission of TFMV.

\section{Volume of parked vehicles}

A key component of the Routine Activity Theory is a suitable target (Cohen and Felson, 1979) and the perceived number of possible targets was a popular consideration for participants before affordances (Gibson, 1988; Gibson, 2015) might be realised. When evaluating whether the depicted locations might constitute an ideal place to commit TFMV offences, an important 'cue' (Brantingham and Brantingham, 1978) or 'prompt' (Wortley, 2017) was the volume of vehicles within a confined space. This fits with what Copes (1999) found for the theft of vehicles. Long roads in neighbourhood areas are likely to be at increased risk because of the volume of vehicles that are parked there (Copes, 1999). For example, after assessing Location 3 [see Appendix], Ali stated: 'that would be like a prime spot really y'know? Coz there's bare [many] cars on the road' whilst Wilson stated that all the locations had some appeal because 'if you just want to rob out of cars, there's a lot there to go $a t^{\prime}$. When probed as to why locations with a high volume of parked vehicles might be an attractive location to commit offences, participants cited a strong link between the number of potential targets and the greater likelihood of an 'opportunity' presenting itself (Wickström, 2006; Wortley, 2012). This was borne out by the responses of Darryl and Colin who supported their initial attraction to the locations by saying: ' $y$ 'know, greater numbers yield greater results' and 'with all those cars and $y^{\prime}$ know, the chances are that someone could have forgot to lock their door'. Whether the vehicles would actually offer the sought after 'results' and means of affordance seemed to be of secondary importance to the initial perception of how many vehicles there were to check for unattended property.

The seeming attractiveness of a road with many observable vehicles (Locations 2 and 3) was matched by less enthusiastic comments about Location 4 because of the fewer vehicles in sight. Darryl commented that: 'there's not a huge amount of cars down there is there? And they're not...they're not especially good cars are they? So there's probably low value stuff in them'. The lack of discernible targets was not the only reason why location 4 appeared less suitable. It was not a situation that prompted offending (Wortley, 1997) because of the perceived effort that would be involved in seeking out opportunity. This was summed up by Dwayne: 
'from them two [vehicles], you got to march about half a mile down the road before you can check the next...there's only about: one, two, three, four, five, six, seven, eight...there's only ten cars on that street and that's about a mile long street or something so you'd think..."it's not worth it."

Whilst Dwayne might have somewhat overestimated the length of the street, his point that Location 4 is likely to yield less reward and more effort than the streets in Location 2 and 3 [see Appendix] is clear. A location with a discernible number of vehicles was offered as a context where TFMV offences were likely to be committed and there were further characteristics said to offer this opportunity. Long streets with many parked vehicles seemed to take on a greater appeal than car parks with many vehicles:

Interviewer: 'but there were lots of cars in the first...in the car park [location 1] and you said that was the safest?'

Brendan: 'yeah, that is the safest. Yeah, but car parks and that y'know...I prefer long streets, more cars.'

When probed why many cars on the street are an important cue to a potential offender, Ali offered a response that substantiated Brendan's preference: 'thieves will go down looking through every single window of them cars'. The reasons why car parks generally did not share this preference had much to do with what participants could see in Location 1 and their knowledge (Wickström, 2006) of security measures likely to be present. Jason observed that Location 1 has 'loads of cars in it but there's also cameras. There's cameras everywhere'. Paul described how 'they've all got people watching the cameras so if you see someone walking around for fifteen minutes going from floor level to floor level in the car park, it's gonna bring attention to you'. Amongst the participants interviewed, Location 1 seemed to invite more caution than the other three locations.

This is not to suggest that the car park was not deemed by any participants to be a suitable target or that surveillance was always interpreted as a measure to be wary of. For one participant, even the likelihood of car park surveillance was not a sufficient deterrent. After viewing Location 1, Mark's impression was: 'it looks like CCTV cameras are around. I'm not 100\% sure but that's what it looks like. It's not gonna bother...bother us to be honest. Me, I've been in car parks similar to this and put car windows through'. Generally, the attractiveness of a high volume of vehicles parked on the street outweighed the attractiveness of a car park full of vehicles. The presentation of locations containing what were perceived as a high number of vehicles evoked prompts and provocations (Wortley, 2017) that there might be suitable targets (Cohen and Felson, 1979) nearby. Before examining possibilities for affordance (Gibson, 1988; Gibson, 2015) at these locations, it is necessary to further unpack what else seemed to lead to target suitability. 


\section{The presence of cover}

Another key consideration of whether to frequent an area in search of offending opportunity concerned the amount of cover offered within the location. If there was a discernible amount of cover in a location, this added further appeal as it was said to decrease the likelihood of detection. One form of cover could be the vegetation in Location 3 [see Appendix] as Dwayne describes: 'that one's quite easy really coz that's just.... that there, like hedges and stuff, they're...they're good coz they conceal'. Mark shared a similar line of thinking: 'not the side with the Transit [van] but the other side where the fence and the bushes are, you can hide like down the side and play about [with the vehicle]'. The presence of substantial vegetation could also serve as a useful route of escape for the offender. Ross recognised that 'it's surrounded by trees which would...if you were gonna get away... would aid me. D'you know what I mean? Because I could quite easily just disappear into the trees'. This evokes a pertinent link between the way the built environment is perceived by a potential offender and Wortley's (2017) notion of 'triggers that prompt'. An individual can be introduced to specific features within a location which promptly trigger a physiological response (Wortley, 2017) and possible affordances (Gibson 1988, Gibson, 2015). In this case, former offenders spotted physical features such as bushes, hedges and trees and soon began an evaluation of how they might adapt their behaviour.

The attraction to vehicles with cover on one side and a hidden escape route offers good reason why they were considered significantly more preferable than those parked in, or close to, residential driveways. When probed as to why the vehicles on a covered side of the road were preferable to the vehicles that were not, the possibility of onlookers inside the properties was offered as a point of caution. This was particularly a factor at night. Brendan claimed that 'not many people like to walk on a driveway coz of the lights' and Mark observed that 'in location three, there are houses next to that Transit van so surely people could be looking at you'. A property in close proximity to a vehicle comprises a 'friction' (Wickström, 2006) due to its deterrent effect. Whilst overlooking residential properties might not prevent victimisation against all of the vehicles on the road, they served as a 'cue' (Brantingham and Brantingham, 1978) that theft from certain vehicles carried more risk than others. Once more, the possibility of onlookers within the properties did not deter all interviewees; Dwayne stated:

'it doesn't fuckin' matter mate coz no one can't see ya...if ya....if I'm right against those houses like standing against the doors like that [makes gesture], on this one [location 3]....then no one can't see me nowhere unless there's people in that park or there's passers-by.'

The significance of passers-by is now addressed and is followed by our first instance of affordance. 


\section{Passers-by and one-way roads}

Alongside the caution that should be exercised because of possible onlookers inside properties, participants assessed the likelihood of passers-by. This influenced both the time when individuals would select potential targets and where they would be selected from. Luke 'used to go out about ten, twelve o'clock at night when no one's about and just pick an estate and try every car door'. The ideal time for Colin was: 'definitely at night. Well, day is too bright; there's too many people around'. The preference of Brendan was similar:

Brendan: around half one, two o'clock in the morning.

Interviewer: coz there's no one about?

Brendan: yeah.

Interviewer: yeah? And

Brendan: more people sleeping.

Preoccupation with possible passers-by meant that participants were particularly attracted to Location 2 [see Appendix] because of one of its visible physical features. The road sign which indicates 'no entry' served as a cue that disturbance from 'passers-by', or even the police, might be less likely. When asked why he mentioned that Location 2 depicts a 'one way road', Colin said 'because then people can't get in ermm...up that way so if you were taking something, you don't have to worry about cars coming up that way'. A further example of this was offered by Don: 'no police would come the other way; well, more than likely wouldn't come from down the road because they look like no entry signs at the top of the road'. Participants stated that roads with 'no entry' signs can be attractive locations to offend because there is a possibility of oncoming vehicles from only one side.

If the desired goal or intention (Ekblom, 2012; Gibson, 2015) of the TFMV offender is to operate without disturbance, the affordance of the road sign can be perceived as a positive prompt for engagement (Ekblom, 2012). The road sign takes on significance beyond its conventional understanding. For the 'unlikely' offender (see Cohen and Felson, 1979), it might be deduced from the 'no entry' sign that vehicles are not permitted entry to the road. For the 'likely' offender (Cohen and Felson, 1979), the 'no entry' sign might signify this but also afford that the road is a suitable place to successfully commit offences. It might not be the determining factor as to whether the vehicles are targeted but this form of road sign seemed to add to the attractiveness of the location. With a desire of the offender to minimise the likelihood of passers-by, the 'one way' road can be a 
useful indicator of where to offend. A law-abiding individual who has little interest in whether they are noticed and scant experience of the ideal conditions for stealing property are likely to be oblivious to these characteristics. Felson's (2014) expansion upon Hirschi's (1969) Control Theory is crucial to understanding this. Society possesses a handle on some individuals that acts as an informal social control to prevent the thought of opportunist law-breaking (Felson, 2014). For those whom this handle is ineffective, there is a wealth of opportunity to be realised and offending choices to be made (Felson, 2014). What is fundamental is criminal inclination (Felson, 2014), the desired goal of the individual (Ekblom, 2012) and weak individual morality (Wickström, 2006). It is at this point that cues, like variant interpretations of road signs, learned through experience or social transmission can avail themselves to motivated individuals (Andresen et al. 2010).

\section{Fitting in}

Some physical properties of a suitable location to offend have been addressed; attention now turns to what participants offered as befitting ways to frequent these locations so as to avoid suspicion. Sometimes this involved acting or dressing in a certain way. In terms of what to wear, Dwayne considered it an advantage to dress casually but not so casually that people in the vicinity would associate you with not belonging there or being up to no good:

Dwayne: just put err...jeans and a t-shirt on. A Jack Jones T-shirt and a pair of jeans and then gel ya hair.

Interviewer: and?

Dwayne: and just stroll about. No one don't look at you like that but if you're in a tracksuit, they look at ya. It's stereotypical.

Dwayne's second point involved dressing as though you were, or had been, conducting legitimate work: 'a lot of people put high vis [high visibility clothing] on and stuff, to do y'know [illegitimate things]'. This comprises an example of affordance since the 'likely' offender (Cohen and Felson, 1979) selects something they would not normally wear and uses it for the express purpose of committing offences undetected. A more common usage for a t-shirt and jeans in public might be to wear comfortable clothing or because the wearer deems these to be stylish. In this case, clothing is being worn to assist a 'likely' offender (Cohen and Felson, 1979) to fit into the surroundings of where they hope to offend. Alternatively, and in an ecological sense (see Gibson, 1988; Gibson, 2015), high visibility clothing can help the offender to survive within their immediate environment without apprehension; detection would be akin to an organism being preyed upon by another. The 
offender perceives the affordance (Gibson, 1988; Gibson, 2015) of this clothing to the extent that it can help seek out suitable vehicles to steal from. The response of Dwayne implies that one is less likely to be challenged when wearing clothing associated with conducting work in public. Members of the general public would be likely to accept this as an indication of official personnel; a similar scenario to this occurred in 2014 during a theft of heritage railway property (see Telegraph \& Argus, 2014).

In terms of how one acts whilst looking for targets, several instances were given. Two of them included behaving as if you have definite intentions to enter a vehicle (that people will think you are the owner of) and acting somewhat inebriated so that, if there are onlookers, they do not think you have intentions to enter a vehicle. Lawrence recalled: 'if you see a car open, just blatantly go in it. Make out it's your own car' and Don's recollection, applicable for two offenders, was that: 'you'd just walk as if you was both just coming back from a night out or maybe put on a bit of a zig-zag as if you'd had a drink'. In both of these examples, it is the spaces surrounding the vehicles that are being afforded to in different ways (Gibson, 1988; Gibson, 2015). The comportment of the offender is disingenuous in order to mask their actual intentions: the theft of property from a vehicle.

\section{Breaking In}

In this last section, insight is given into some of the techniques that might be used and objects afforded to, once a suitable location and vehicle has been selected by the offender. As conveyed by an example in the previous section, the modus operandi of some who commit TFMV is simply to check for an unlocked door. For others such as Paul, Dwayne and Don, tools which usually have other uses are brought to the scene of the crime. Implements mentioned during the interviews included: spark plugs, hammers to escape an auto bus (in an emergency) and flat-headed screwdrivers. Paul mentioned the utility of spark plugs and gave a rather explicit account of how to break into a vehicle. As a result, his account can only be partially included here:

'it's got a very sharp point you push and you go so far down and it goes (makes clicking noise)...and it...[the rest has been omitted]

This was a technique that Dwayne could also offer a description of: 'you can smash a spark plug and the white bits off the spark plug shatter and you can get a little piece of that and, believe this or not, to get in you go (makes whipping noise) and it goes (makes shattering noise).' 
Don mentioned the requirement to 'use a screwdriver and just break the window' whilst Paul also made clear that hammers taken from buses can shatter glass instantly and quietly. With all of these examples, there is evidence of the meaning and usage of objects being perceived differently (Gibson, 1988; Gibson, 2015) to their more conventional usage. Just as a 'wheelie bin' can be used to store stolen goods instead of refuse (Garwood, 2009), a spark plug can be carried and used to break into a vehicle instead of igniting an engine. Once more, the desired goal of the individual (Ekblom, 2012) has a significant bearing on the possible means which can be used to reach that end. In many respects, an applied analysis of the concept of affordance within a crime context reveals a certain creativity that might otherwise go unnoticed. In each of these five sections, it has been established that there is a discernible preference for the type of location in which to offend, and once these have been found, for the items afforded to. These findings add strength to Nee and Taylor's (2000) findings for property offences in that, far from randomly selecting targets, the TFMV offender shows signs of intuition about where to commit offences.

\section{Discussion and Conclusion}

The successful commission of Theft from Motor Vehicle appears more likely to occur in certain locations based upon the interpretations of situational cues examined here. The affordance of some objects and how they facilitate offending has been offered within these accounts of former offenders. Whilst the content of these accounts proved to be largely informative, it is necessary to rehearse limitations of such a source. The fact interviews involved individuals on probation meant participants had been convicted of at least one TFMV offence which calls into question whether this sample were effective in remaining undetected (Jacques and Bonomo, 2017). It has also been stated that offenders may distort the truth because revealing too much is risky (Jacques and Bonomo, 2017) but this reveals a strength of this sample as well. The recruitment of participants who were fulfilling a probation license meant that they were undergoing community rehabilitation and so actually might be more likely to share details of a past time that they were trying to put behind them. Nonetheless, and as instructed by Jacques and Bonomo (2017), future research in this area might seek to include the accounts of those who have successfully evaded detection.

Furthermore, within the qualitative interviews conducted, time constraints meant that only four locations could be subject to investigation. There are undoubtedly more contexts than this that express vulnerability to those who seek to commit TFMV. These too could serve as useful tools and lead to informative discussion with offenders. Although these findings provide a foundation, participants were recruited from only one county in England so there is scope to broaden this 
sample. There might be some differences in the responses of individuals under the age of 18 and how they find suitable targets; this study included only participants over the age of 18 . There are ways to further test the validity of responses and extend the study by making use of virtual reality scenarios. For example, one could undertake analysis of micro-movements and eye-tracking (see van Gelder et al. 2017) to assess what, and how quickly, cues are assessed by individuals. Nee et al. (2015) used domestic burglary simulations to elicit different approaches between novice and expert burglars; this provides a useful benchmark for the use of such methods to examine offender decision-making.

The results of this qualitative inquiry have provided strong evidence to suggest there are some situational cues that signal attractiveness to an individual seeking to commit Theft from Motor Vehicle. These included: long roads with lots of parked vehicles, roads with cover along one side and places where the number of passers-by are fewer. In addition, participants showed good knowledge of possible items that can be brought to and utilised in these locations. Examples included: spark plugs, hammers from buses and flat-headed screwdrivers. Whilst no-one would seriously suggest a ban on spark plugs, it might be worth ensuring that beat officers are familiar with the potential illicit use of such items. Other measures might be to link alarms to emergency hammers on public transportation to help ensure they are only used for their intended purposes. A pressing intervention would also be to make recommendations, in areas with the discussed vulnerable characteristics, about the importance of not leaving obtainable property inside or on motor vehicles. Leicestershire Police (2018) have drawn the attention of citizens to the slogan 'Leave it on show, expect it to go' to increase awareness about the activity of offenders who specifically target obtainable property from motor vehicles. The programming of audible reminders within vehicles to remove valuables upon parking (Clarke and Harris, 1992; Felson, 1994) could prove to be an effective solution as well.

Agencies that work towards the prevention of crime should seek to make these contexts less attractive to the offender(s) who operates with the discussed preferences. They could put pressure on car manufacturers to improve the security and alarm systems of these vehicles - perhaps by reinstating a version of the Car Theft Index that was last published in 2006. At a local level, agencies could proactively inform potential targets in vulnerable locations of their increased risk of victimisation. This was successfully trialled as part of a package of measures in Operation Cobra in Portsmouth in 2004 (Earle and Edmunds, 2004). Increasing the risk to the offender of being caught, rather than penalties if they are prosecuted is key: unsurprisingly, the principal appeal for nearly all respondents lay in the possibility of continually being able to offend undetected and therefore without apprehension. 


\section{$\underline{\text { References }}$}

Andresen, M. A., Brantingham, P. J., Kinney, J. B., (2010) Classics in Environmental Criminology, British Columbia: Simon Fraser University Publications.

Armitage, R., (2017) Design, Crime and the Built Environment. In. Tilley, N., and Sidebottom, A., (eds.) Handbook of Crime Prevention and Community Safety. $2^{\text {nd }}$ Edition. Oxon: Routledge. Chapter 11.

Armitage, R., (2018) Burglars' take on crime prevention through environmental design (CPTED): reconsidering the relevance from an offender perspective, Security Journal, 31: 285-304.

Ashton, J., Brown, I., Senior, B., and Pease, K., (1998) Repeat Victimisation: Offender Accounts, International Journal of Risk, Security and Crime Prevention, 3 (4) 269-279.

Bennett, T., and Wright, R., (1984) Burglars on Burglary. Aldershot: Gower.

Brantingham, P. J., and Brantingham, P. L., (1978) A Theoretical Model of Crime Site Selection. In Krohn, M., and Akers, R., (eds.) Crime, Law and Sanctions, Beverley Hills: Sage.

Brantingham, P. J., and Brantingham, P. L., (1981) Environmental Criminology. Illinois: Waveland Press.

British Society of Criminology., (2006) Code of Ethics. (online) Available at:

http://www.britsoccrim.org/docs/CodeofEthics.pdf [Accessed 01.09.2017].

Bromley, R., Thomas, C., (1997) Vehicle Crime in the City Centre: Planning for Secure Parking, The Town Planning Review, 68 (2) 257-278.

Bryman, A., (2016) Social Research Methods, $5^{\text {th }}$ Edition. Oxford: Oxford University Press.

Clarke, R. V., and Harris, P. M., (1992) Auto theft and its prevention. In M. Tonry (eds.) Crime and justice: A review of research (Vol. 16, pp. 1-54). Chicago University: Chicago University Press.

Cohen, L. E., and Felson, M., (1979) Social Change and Crime Rate Trends: A Routine Activity Approach, American Sociological Review, 44: 588-608.

Copes, H., (1999) Routine Activities and Motor Vehicle Theft: A Crime Specific Approach, Journal of Crime \& Justice Volume, 22 (2) 125-146.

DLNR CRC., (2014) Derbyshire Leicestershire Nottinghamshire \& Rutland Community Rehabilitation Company: Transforming Lives, Reducing Crime (online) Available at: https://dlnrcrc.co.uk/wpcontent/uploads/2014/07/DLNR-LF-018 The-DLNR-CRC-Ltd-About-Us.pdf [Accessed 31.01.2018] 
Earle, J. and Edmunds, A. (2004) Operation Cobra. Available at

http://www.popcenter.org/library/awards/tilley/2004/04-71(R).pdf [accessed 26.09.2017]

Ekblom, P., (2012) Conceptual and Methodological Explorations in Affordance and Counter Terrorism. In. Taylor, M., and Currie, P. M., (eds.) Terrorism and Affordance, London: Continuum. Chapter 3.

Felson, M., (1994) Crime and everyday life: insights and implications for society. Thousand Oaks, California: Pine Forge Press.

Felson, M., (2014) Linking Criminal Choices, Routine Activities, Informal Control, and Criminal Outcomes. In. Cornish, D. B., and Clarke, R. V., (eds) The Reasoning Criminal: Rational Choice Perspectives on Offending. New Brunswick, New Jersey: Transaction Publishers. Chapter 8.

Garwood, J., (2011) A quasi-experimental investigation of self-reported offending and perception of criminal opportunity in undergraduate students, Security Journal, 24 (1) 37-51.

Gibson, E. J., (1988) Exploratory Behaviour in the Development of Perceiving Acting, and the Acquiring of Knowledge, Annual Review of Psychology, 39: 1-41.

Gibson, J. J., (2015) The Ecological Approach to Visual Perception, Classic Edition. New York: Psychology Press.

Gov.uk., (2017) Home Office Counting Rules for Recorded Crime: Vehicle Offences (online) Available at: https://www.gov.uk/government/uploads/system/uploads/attachment data/file/602805/countvehicle-apr-2017.pdf [Accessed 01.09.17].

Grove, L., (2011) Preventing Repeat Domestic Burglary: A Meta-Evaluation Of Studies From Australia, the UK, and the United States, Victims and Offenders, 6:370-385.

Grove, L. E., and Farrell, G., (2012) Once Bitten, Twice Shy: Repeat Victimization and Its Prevention. In. Welsh, B. C., and Farrington, D. P., (eds.) The Oxford Handbook of Crime Prevention. Oxford: Oxford University Press. Chapter 20.

Grove, L. E., Farrell, G., and Farrington, D. P., and Johnson, S. D., (2012) Preventing repeat victimization: A systematic review. Stockholm, Sweden: The Swedish National Council for Crime Prevention.

Hirschi, T., (1969) Causes of Delinquency. California: University of California Press. 
Jaques, S., and Bonomo, E., (2017) Learning from the Offender's Perspective on Crime Prevention. In: Leclerc, B., and Savona, E. U., (eds.). Crime Prevention in the $21^{\text {st }}$ Century. Chapter 2. Switzerland: Springer International Publishing.

Johnson, S. D., Summers, L., and Pease, K., (2006) Vehicle Crime: Communicating Spatial and Temporal Patterns. London: UCL Jill Dando Institute of Crime Science.

Johnson, S. D., Summers, L., and Pease, K., (2009) Offender as Forager? A Direct Test of the Boost Account of Victimization, Journal of Quantitative Criminology, 25: 181-200.

Johnson, S., (2010) A brief history of the analysis of crime concentration, European Journal of Applied Mathematics, 21 (4-5) 349-370.

Lab, S. P., (2016) Crime Prevention: Approaches, Practices, and Evaluations, $9^{\text {th }}$ Edition. Oxon: Routledge.

Lasky, N. V., Fisher, B. S., and Jacques, S., (2017) 'Thinking thief' in the crime prevention arms race: Lessons learned from shoplifters, Security Journal, 30 (3) 772-792.

Lee, Y., Eck, J. E., SooHyun, O., \& Martinez, N. N. (2017). How concentrated is crime at places? A systematic review from 1970 to 2015. Crime Science, 6 (1), 6.

Leicestershire Police., (2018) Current local priorities: To reduce the incidents of vehicle crime. (online) Available at: https://leics.police.uk/local-policing/city-centre [Accessed 31.01.18]

***** University., (nd) Ethics Approvals (Human Participants) Sub-Committee. (online) Available at: http://www.lboro.ac.uk/media/wwwlboroacuk/content/universitycommittees/ethicsapprovalshum anparticipantssub-committee/Data\%20Collection\%20and\%20Storage.pdf [Accessed 31.01.18]

Mailley, J., Garcia, R., Whitehead, S., Farrell, G., (2008) Phone Theft Index, Security Journal, 21 pp. 212-227.

Nee, C., and Taylor, M., (2000) Examining Burglars' target selection: Interview, experiment or ethnomethodology?, Psychology, Crime \& Law, 6 (1) 45-59.

Nee, C., (2003) Research on Burglary at the End of the Millenium: A Grounded Approach to Understanding Crime. Security Journal, 16 (3) 37-44.

Nee, C., and Meenaghan, A., (2006) Expert decision making in burglars. British Journal of Criminology, 46 (5) 935-949. 
Nee, C., (2010) Research on residential burglary: ways of improving validity and participants' recall when gathering data. In. W. Bernasco. (2010) (eds.) Offenders on Offending: learning about crime from criminals. Devon: Willan Press.

Nee, C., White, M., Woolford, K., Pascu, T., Barker, L., \& Wainwright, L. (2015). New methods for examining expertise in burglars in natural and simulated environments: preliminary findings.

Psychology, Crime \& Law, 21(5), 507-513.

Newman, G., Clarke, R. V., Shoham, S. G., (2016) Rational Choice and Situational Crime Prevention. Oxon: Routledge.

Norman, D. A., (1988) The Design of Everyday Things, New York: Basic Books.

Office for National Statistics., (2017) Overview of vehicle-related theft : England and Wales. (online) Available at

https://www.ons.gov.uk/peoplepopulationandcommunity/crimeandjustice/articles/overviewofvehic lerelatedtheft/2017-07-20 [Accessed 01.08.17].

Palmer, E. J., Holmes, A., Hollin, C. R., (2002) Investigating Burglars' Decisions: Factors Influencing Target Choice, Method of Entry, Reasons for Offending, Repeat Victimisation of a Property and Victim Awareness, Security Journal, 15 (1) 7-18.

Pease, K. (1998). Repeat Victimisation: Taking Stock. Crime Prevention and Detection Series Paper 90. London: Home Office.

Pease, K., and Laycock, G., (1999) Revictimisation: Reducing the Heat on Hot Victims, Australian Institute of Criminology, 128, 1-6.

Police.uk., (2017) Crime and policing in England, Wales and Northern Ireland. (online) Available at: https://www.police.uk/ [Accessed 01.08.17]

Polišenská, V. A., (2011) Interviewing offenders in a penitentiary environment and the use of mental maps during interviews. In. Bernasco, W., (eds) Offenders on Offending: Learning about crime from criminals. Oxon: Routledge. Chapter 15.

Saunders, M. N. K., (2006) Gatekeeper. In. Jupp, V., (eds.) The Sage Dictionary of Social Research Methods. London: Sage.

Sherman, L. W., Gartin, P. R., \& Buerger, M. E. (1989). Hot spots of predatory crime: Routine activities and the criminology of place. Criminology, 27(1), 27-56. 
Spelman, W., \& Eck, J. E. (1989). Sitting ducks, ravenous wolves and helping hands: new approaches to urban policing. Austin, TX: Lyndon B. Johnson School of Public Affairs, University of Texas at Austin.

Suresh, G., and Tewksbury, R., (2012) Locations of Motor Vehicle Theft and Recovery, American Journal of Criminal Justice. 3 (8) 200-215.

Telegraph \& Argus., (2014) Video: Brazen thieves in high-vis jackets steal benches from heritage station. (online) Available at:

http://www.thetelegraphandargus.co.uk/NEWS/11134840.VIDEO Brazen thieves in high vis jac kets steal benches from heritage station/ [Accessed 26.03.2018]

Temple University., (2015) Near Repeat Calculator, (online) Available at:

http://www.cla.temple.edu/cj/center-for-security-and-crime-science/projects/nearrepeatcalculator/ [Accessed 01.08.2017].

The AA (2012) Reducing Risks: Top tips for reducing car crime. (online) Available at: http://www.theaa.com/motoring advice/security/reducing risk.html [Accessed 29.01.18].

The DLNR CRC., (2014) Transforming Lives, Reducing Crime, (online) Available at: https://dlnrcrc.co.uk/wp-content/uploads/2014/07/DLNR-LF-018 The-DLNR-CRC-Ltd-About-Us.pdf [Accessed 01.08.17].

Tilley, N. (1993). After Kirkholt: Theory, method and results of replication evaluations. Home Office Police Department.

Van Gelder, J. L., Nee, C., Otte, M., Demetriou, A., van Sintemaartensdijk, I., van Prooijen, J. W., (2017) Virtual Burglary: Exploring the Potential of Virtual Reality to Study Burglary in Action, Journal of Research in Crime and Delinquency, 54 (1) 29-62.

Webb, B., and Brown, R., (2017) Preventing Vehicle Crime. In. Tilley, N., and Sidebottom, A., (eds.) Handbook of Crime Prevention and Community Safety, Second Edition. Oxon: Routledge. Chapter 16.

Wickström, P. O., (2006) 'Individuals, Settings, and Acts of Crime: Situational Mechanisms and the Explanation of Crime'. In Wickström, P. O., and Sampson, R., (eds.) The Explanation of Crime: Context, Mechanisms and Development. Cambridge: Cambridge University Press. Chapter 3. Wilson, J. Q., and Kelling, G. L., (1982) Broken Windows, Atlantic Monthly, 249 (3) 29-38. 
Wortley, R. (1997). Reconsidering the role of opportunity in situational crime prevention. In: Newman, G., Clarke, R. V., and Shohan, S. G., (eds.) Rational choice and situational crime prevention (pp. 65-81). Aldershot: Ashgate Publishing.

Wortley, R., (2008) Situational precipitators of crime. In. R. Wortley and L. Mazerolle (eds.) Environmental Criminology and Crime Analysis, Cullompton: Willan. Chapter 3.

Wortley, R., (2012) Affordance and Situational Crime Prevention: Implications for counter terrorism. In. Taylor, M., and Currie, P. M., (eds.) Terrorism and Affordance. London: Continuum. Chapter 2.

Wortley, R., and Townsley, M., (2017) Environmental Criminology and Crime Analysis. In. Wortley, R., and Townsley, M., (eds.) Environmental Criminology and Crime Analysis, $2^{\text {nd }}$ Edition. Oxon: Routledge. Chapter 1.

Zetinigg, B., and Gaderer, M., (2011) Validating offenders' accounts: learning from offender interviews with bank robbers in Austrian prisons. In. Bernasco, W., (eds.) Offenders on Offending: Learning about Crime from Criminals. Oxon: Routledge. Chapter 16.

Appendix:

Example 3 of 8 of the visual images that were used during the qualitative interviews - Location 2.

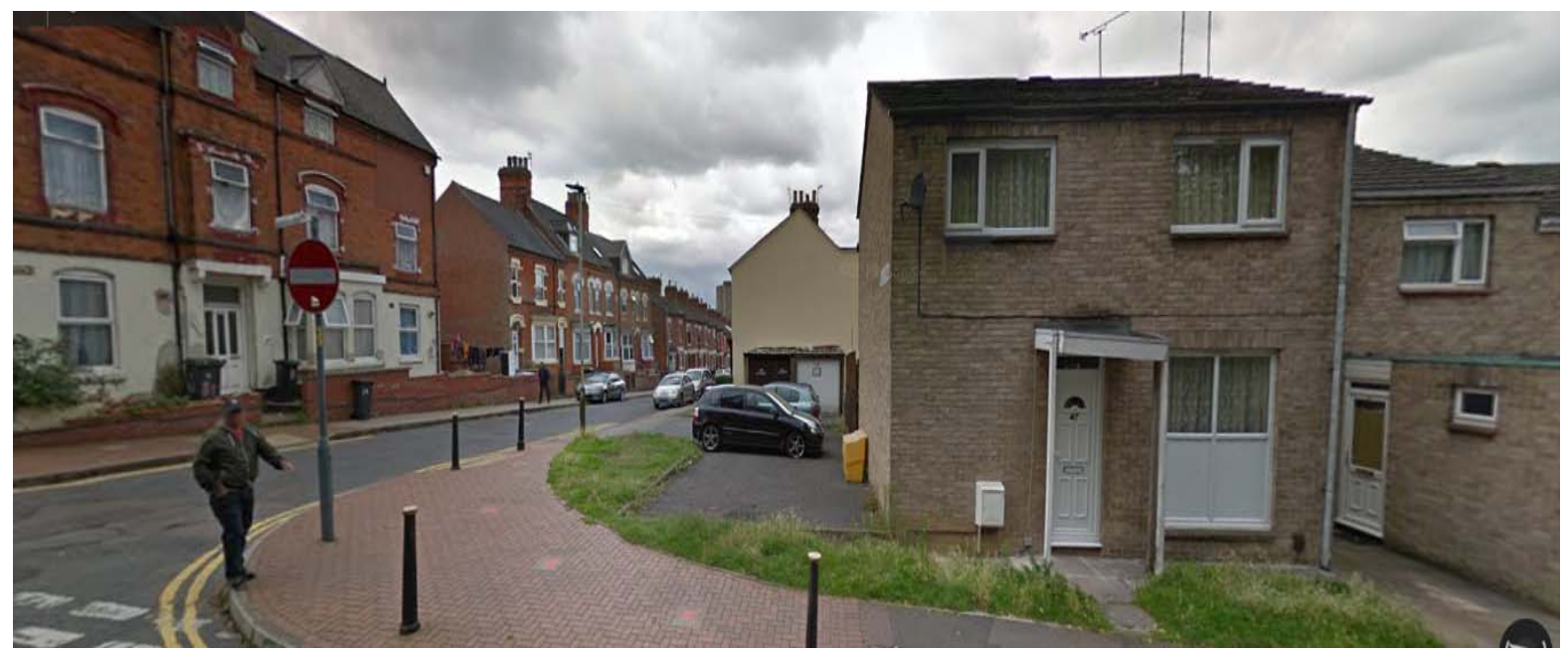

Example 5 of 8 of the visual images that were used during the qualitative interviews. - Location 3. 


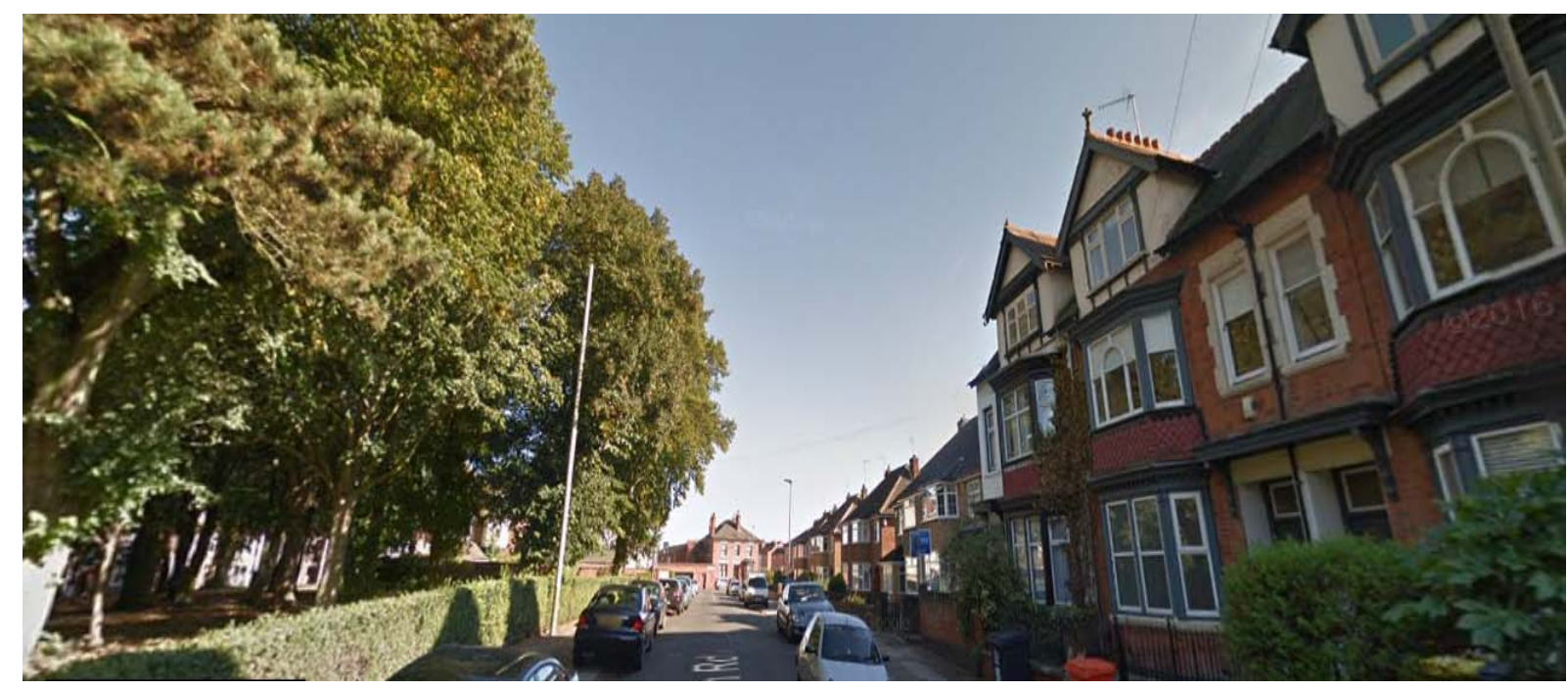

